\title{
Optimizing opioid prescriptions after laparoscopic appendectomy and cholecystectomy
}

\author{
Adina E. Feinberg, MD \\ Sergio A. Acuna, MD, PhD \\ David Smith, MD \\ Brian Kashin, MD \\ Aaron Mocon, MD \\ Brian Yau, MD \\ Jenny Chiu, PharmD \\ Sanjho Srikandarajah, MD
}

Accepted January 21, 2020

\section{Correspondence to: \\ A.E. Feinberg \\ Department of Surgery \\ University of Toronto \\ 30 Bond Street \\ Toronto, ON M5B 1W8 \\ adifeinberg@gmail.com}

DOI: $10.1503 /$ cjs.001319

\begin{abstract}
Background: There has been an increase in opioid usage and opioid-related deaths. Opioids prescribed to surgical patients have similarly increased. The aim of this study was to assess opioid consumption in patients undergoing laparoscopic appendectomy (LA) and laparoscopic cholecystectomy (LC) and to determine whether a standardized prescription could affect opioid consumption without affecting patient satisfaction.
\end{abstract}

Methods: Patients undergoing LA or LC were recruited prospectively during 2 time periods (April to June 2017 and November 2017 to January 2018). In the first phase, surgeons continued their usual postoperative analgesia prescribing patterns. In the second phase, a standardized prescription was implemented. Patients were contacted by telephone and a questionnaire was completed for both phases of the study. The primary outcome was the quantity of opioids prescribed and consumed.

Results: In the first phase, 166 patients who underwent LC or LA were recruited. The median number of prescribed opioid tablets was 20 and the median number consumed was 2. Ninety-five percent of patients reported satisfaction with their analgesia. Based on these results, a standardized prescription for multimodal analgesia was implemented for the second phase, consisting of 10 opioid tablets. In the second phase, 129 patients who underwent LA or LC were recruited. There was a significant decrease in the median number of opioid pills filled (10) and consumed $(0)$, with no difference in reported satisfaction with analgesia.

Conclusion: Patients are prescribed an excess of opioids after LA or LC. Implementation of a standardized prescription based on a quality improvement intervention was effective at decreasing the number of opioids prescribed and consumed.

Contexte : On a observé une augmentation de la consommation d'opioïdes, ainsi qu'une hausse des décès associés à ces substances. On a aussi constaté une augmentation semblable dans la prescription d'opioïdes aux patients ayant subi une chirurgie. La présente étude visait à évaluer la consommation d'opioìdes chez les personnes ayant subi une appendicectomie par laparoscopie (AL) ou une cholécystectomie par laparoscopie (CL), de même qu'à déterminer si une ordonnance normalisée pouvait modifier la consommation d'opioïdes sans nuire à la satisfaction des patients.

Méthodes : Des patients devant subir une AL ou une CL ont été recrutés de façon prospective entre avril et juin 2017 et entre novembre 2017 et janvier 2018. Durant la première phase de l'étude, les chirurgiens ont maintenu leurs habitudes de prescription d'analgésie postopératoire. Durant la deuxième phase, toutefois, ils devaient avoir recours à une ordonnance normalisée. Dans les 2 phases de l'étude, les patients ont été joints par téléphone et un questionnaire a été rempli. Le principal résultat à l'étude était la quantité d'opiö̈des prescrits et consommés.

Résultats : Pour la première phase de l'étude, 166 patients ont été recrutés. Les nombres médians de comprimés prescrits et consommés étaient de 20 et de 2 , respectivement. De tous les patients, $95 \%$ se sont dits satisfaits de leur analgésie. Pour la deuxième phase, une ordonnance normalisée d'analgésie multimodale, qui comptait 10 comprimés, a été mise en place, et 129 patients ont été recrutés. On a alors observé une diminution significative du nombre médian de comprimés remis (10) et consommés (0), et aucune différence quant au degré de satisfaction déclaré.

Conclusion : Les patients se voient prescrire trop d'opioïdes après une $\mathrm{AL}$ ou une CL. La création d'une ordonnance normalisée dans le cadre d'une intervention d'amélioration de la qualité a réduit efficacement le nombre de comprimés d'opioïdes prescrits et consommés. 
$\mathbf{T}$ he use of opioids to manage pain has increased substantially since the 1990 s, with some serious unintended consequences. ${ }^{1,2}$ The increase in opioid pharmaceutical sales has been followed by a parallel increase in opioid-related deaths. ${ }^{3,4}$ In Canada, Ontario is the province with the highest rate of opioid dispensing. ${ }^{5}$ The number of opioids prescribed to postoperative patients has similarly increased over time. ${ }^{6}$ A Canadian population-based study examining opioid-naïve elderly patients who underwent low-pain short-stay surgery found that $10 \%$ were long-term opioid users at 1 year postsurgery. ${ }^{7}$ Other Canadian studies have reported longterm opioid use in $0.4 \%-3.0 \%$ of patients after major surgery. 8,9 Moreover, the risk of opioids extends beyond the individual who received the original prescription, as opioids may be misused or diverted to others. ${ }^{3,10}$ The presence of opioids in a household is known to put children at risk. ${ }^{11}$ According to the 2017 Centre for Addiction and Mental Health Ontario Student Drug Use and Health Survey, 11\% of high school students report nonmedical use of opioids; $55 \%$ of the time the opioids were obtained from home. ${ }^{12}$ Younger adults are at high risk for opioid-related death, with 1 in 8 deaths among people aged $25-34$ being opioid-related. ${ }^{13}$ Excessive prescribing of opioid medications to postoperative patients therefore has negative effects by contributing to both long-term patient use and mishandling of unused opioids. Addressing the opioid epidemic is complex and requires multiple strategies, but an important component is more judicious prescribing by physicians.

A recent Canadian guideline on the use of opioid therapy for chronic pain emphasizes harm reduction and proposes limiting opioid perscription. ${ }^{14}$ However, at the time this study was initiated, there were no clear guidelines advising on appropriate prescribing after specific surgical procedures. There are currently guidelines available from the Michigan Opioid Prescribing Engagement Network and a Canadian guideline is in production from the Best Practice in Surgery Group. ${ }^{15,16}$ Several American studies have reported wide variation in opioid prescription practices and an excess of unused opioids in general surgery patients. ${ }^{17-19}$ These excess, unused opioids are rarely disposed of properly. ${ }^{19,20} \mathrm{We}$ sought to characterize postdischarge opioid prescription in a cohort of patients undergoing laparoscopic appendectomy (LA) or cholecystectomy (LC) in a Canadian hospital. Our goal was to minimize excess opioid prescription. This quality improvement project sought to determine the amount of opioids used by surgical patients following discharge and then optimize opioid prescription to match this usage pattern. The primary outcome was the quantity of opioids prescribed and consumed. Secondary outcomes included the adequacy of pain control and patient education on storage and disposal methods for remaining opioid tablets.

\section{Methods}

In the first phase of this study, patients who were undergoing LA or LC were prospectively recruited at a universityaffiliated community hospital between April 2017 and June 2017. Patient discharge prescriptions were provided by general surgery attending physicians or residents who were instructed to continue their usual, routine prescribing patterns. Patients were excluded if they were younger than 18 years of age, non-English speaking or pregnant. Patients were enrolled for the study before their operation on the day of surgery (Appendix 1, available at canjsurg. ca/001319-a1). Informed consent was obtained and patients were contacted by telephone after discharge from hospital on postoperative day 7. Patients completed a standardized questionnaire administered by one of the investigators (Appendix 1). Patients were called up to 3 times on postoperative day 7 , starting at the preferred time frame as indicated at recruitment until they were reached. If they could not be reached on day 7 , they were called once on postoperative day 8 . If they could not be reached on postoperative day 8 , they were deemed lost to follow-up.

Following analysis of phase 1 results, a standardized postoperative discharge pain medication prescription was developed collaboratively between the Anesthesiology, Surgery and Pharmacy departments, with input from hospital patient advisers. A nominal group technique, involving structured decision-making by committee, was used across multiple meetings to arrive at a consensusbased discharge prescription. ${ }^{21}$ This prescription was built into the computerized provider order entry system of the patient electronic health record. Surgeons were informed of the implementation of the new standardized prescription.

In the second phase of this study, prospective recruitment of patients undergoing LA or LC occurred between November 2017 and January 2018 and the same questionnaire was administered to assess the impact of the new standardized pain prescription. In partnership with the Pharmacy department and the Institute for Safe Medication Practices, an educational pamphlet was developed for patients and provided postoperatively upon discharge (Appendix 1). This pamphlet detailed strategies for managing pain at home, information about opioid medications and potential adverse effects, and proper opioid storage and disposal. This information was reviewed with the patients before discharge.

Ethics approval was obtained from the Research Ethics Board at North York General Hospital (NYGH REB \#170011).

\section{Outcomes}

The primary outcome of this study was the quantity of opioid medication prescribed and consumed postdischarge 


\begin{tabular}{|c|c|c|c|c|}
\hline \multirow[b]{2}{*}{ Characteristic } & \multicolumn{2}{|c|}{ First phase, no. $(\%)^{*}$} & \multicolumn{2}{|c|}{ Second phase, no $(\%)^{*}$} \\
\hline & $\begin{array}{l}\text { Laparoscopic } \\
\text { appendectomy } \\
\quad(n=33)\end{array}$ & $\begin{array}{c}\text { Laparoscopic } \\
\text { cholecystectomy } \\
(n=94)\end{array}$ & $\begin{array}{l}\text { Laparoscopic } \\
\text { appendectomy } \\
(n=11)\end{array}$ & $\begin{array}{c}\text { Laparoscopic } \\
\text { cholecystectomy } \\
(n=98)\end{array}$ \\
\hline Age, median (IQR) & 45 (33-54) & $51(38-62)$ & 55 (39-68) & $51(43-61)$ \\
\hline Female sex & $14(42.4)$ & 66 (68.8) & $7(63.6)$ & 76 (77.6) \\
\hline Emergency procedure & $30(90.9)$ & $18(18.7)$ & $10(90.9)$ & $15(15.3)$ \\
\hline Conversion to open & 0 & 0 & 0 & 0 \\
\hline History of addiction & $1(3)$ & $1(1)$ & 0 & 0 \\
\hline History of psychiatric illness & $3(9.1)$ & $8(8.3)$ & $2(18.1)$ & $9(9.2)$ \\
\hline History of chronic pain & $1(3)$ & $9(9.4)$ & $2(18.1)$ & $3(2)$ \\
\hline Prior long-term opioid use & $1(3)$ & $3(3.1)$ & 0 & $1(1)$ \\
\hline
\end{tabular}

Table 2. Opioid prescription, use and disposal by procedure during phase I

\begin{tabular}{|c|c|c|}
\hline Variable & $\begin{array}{l}\text { Laparoscopic appendectomy } \\
\qquad(n=33)\end{array}$ & $\begin{array}{l}\text { Laparoscopic cholecystectomy } \\
\qquad(n=94)\end{array}$ \\
\hline Postoperative opioids prescribed, no. (\%) & 31 (93.9) & $94(100)$ \\
\hline Number of pills prescribed, median (IQR) & $20(20-30)$ & $20(15-30)$ \\
\hline Morphine equivalents prescribed, median (IQR) & $150(112.5-150)$ & $112.5(67.5-225)$ \\
\hline Patients not using any opioids, no. (\%) & $11(35.5)$ & $34(36.2)$ \\
\hline Number of pills taken, median (IQR) & $3(0-7)$ & $2(0-5)$ \\
\hline Morphine equivalents taken, median (IQR) & $22.5(0-45)$ & $9.5(0-31.5)$ \\
\hline Number of pills not taken, median (IQR) & $19(13-20)$ & $18.5(10-26)$ \\
\hline Morphine equivalents not taken, median (IQR) & $126(90-150)$ & $95(14-180)$ \\
\hline $\begin{array}{l}\text { Patients still taking opioids at postoperative day } 7 \text {, } \\
\text { no. (\%) }\end{array}$ & $3(9.1)$ & $4(4.2)$ \\
\hline $\begin{array}{l}\text { Pain scores (out of } 10 \text { ) at postoperative day } 7 \text {, } \\
\text { median (IQR) }\end{array}$ & $3.5(2-5)$ & $4(3-5)$ \\
\hline Satisfaction with analgesia, no. (\%) & $32(96.7)$ & $90(95.7)$ \\
\hline $\begin{array}{l}\text { Received education on disposing of unused opioids, } \\
\text { no. }(\%)\end{array}$ & $3(9.1)$ & $7(7.4)$ \\
\hline Disposed unused opioids, no. (\%) & 0 & $4(4.2)$ \\
\hline $\mathrm{IQR}=$ interquartile range & & \\
\hline
\end{tabular}

interquartile ranges (IQR), stratified by study phase. Similarly, histograms are used to present prescribed and used MME by surgical procedure and by study phase. Univariate comparisons were done using $\chi^{2}$ and the Wilcoxon Rank Sum tests. Pearson correlation was used to explore the correlation between continuous variables. Lastly, a multivariable linear regression was used to determine factors independently associated with MME used. Variables included in the model were selected a priori and checked for collinearity. All tests were 2 -sided, with a $p$ value of $<0.05$ considered statistically significant. Data management and analyses were performed using SAS version 9.4 (SAS Institute Inc.).

\section{Results}

\section{First phase}

Between April and June of 2017, 118 patients underwent LA and 212 under- from hospital, measured in number of pills, as well as morphine milligram equivalents (MME). For patients receiving the standardized prescription during phase 2, the number of pills/MME dispensed by the pharmacy was counted as the total number of pills prescribed, regardless of the number of partial fills used to attain that total number. Secondary outcomes included adequacy of pain management, which was measured using pain scores on a numeric rating scale $(0-10)$ on postoperative day 7 , as well as patient satisfaction with analgesia (rated as very satisfied, satisfied, somewhat satisfied, somewhat unsatisfied, unsatisfied or very unsatisfied). Other outcomes included characterizing patients' methods of disposal and storage of unused opioids, and whether a refill opioid prescription was required.

\section{Statistical analysis}

Baseline characteristics and outcomes by surgical procedure are presented using proportions, percentages, medians and went LC. Of these, 166 patients (50\%) met the eligibility criteria and were recruited into the study. A total of 127 patients $(76 \%)$ were reached for follow-up, including 33 patients who underwent LA and 94 patients who underwent LC. The baseline characteristics of each group are displayed in Table 1. Of note, there was a higher proportion of emergency operations among patients undergoing LA (91\%) compared to patients undergoing LC (19\%). There was a higher proportion of female patients in the LC group (70\% v. $42 \%)$. Most patients were discharged on postoperative day 0 or 1 .

Most patients were discharged home with a prescription for opioids (Table 2). A total of 2622 pills were prescribed and $458(18 \%)$ were consumed. The median number of opioid pills prescribed was 20 (IQR 15-30) in both the LA and LC groups. About 35\% percent of patients in both LA and LC groups did not use any opioids. The median number of pills consumed across both groups was 2 (IQR 0-5). In both groups, $75 \%$ of patients used 7 or fewer opioid 
pills. Fifteen (11\%) patients consumed more than 10 pills. These numbers were similar when calculated using MME. Fewer than $10 \%$ of patients in both groups were still using opioids on postoperative day 7. Pain scores were less than 5 in both groups at this time, and more than $95 \%$ of patients reported being satisfied or very satisfied with their analgesia. Fewer than $10 \%$ of patients in both groups reported receiving education regarding disposal of unused opioids and fewer than $5 \%$ had disposed of the unused opioids at the time of interview.

A histogram displaying the distribution of opioids used and opioids prescribed is shown in Figure 1.

\section{Development of the standardized prescription}

Results of the first phase were formally presented to surgeons and surgical residents. Initially, we proposed the introduction of a standardized prescription for LAs or LCs, consisting of 10 opioid-containing pills along with multimodal analgesia, as per the amount used by the 80th percentile of phase 1 patients (Table 3 ). This standardized prescription was created in collaboration with the departments of Surgery, Anesthesia and Pharmacy, with input from hospital patient advisers. During discussions, there was concern among providers that a prescription of 10 tablets would lead to decreased patient satisfaction and a need for refills, given that $15 \%$ of patients used more than 10 tablets. In Ontario, prescribers cannot provide a refill option for an opioid prescription, but they can prescribe opioids as partial fills (i.e., total quantity with number of tablets that can be dispensed over a given interval). Therefore, the final standardized prescription consisted of 10 tablets of either morphine $(5 \mathrm{mg})$ or hydromorphone $(1 \mathrm{mg})$ to be taken every 4 hours, as needed. The

Table 3. Proposed standardized prescription for postoperative laparascopic appendectomy or cholecystectomy patients based on 80 th percentile of opiods consumed in phase 1

\begin{tabular}{lcccc|}
$\begin{array}{l}\text { Surgical } \\
\text { procedure }\end{array}$ & Morphine & Codeine & Oxycodone & Hydromorphone \\
\hline $\begin{array}{l}\text { Laparoscopic } \\
\text { appendectomy }\end{array}$ & $45 \mathrm{mg}$ & $300 \mathrm{mg}$ & $30 \mathrm{mg}$ & $9 \mathrm{mg}$ \\
\hline $\begin{array}{l}\text { Laparoscopic } \\
\text { cholecystectomy }\end{array}$ & $37.5 \mathrm{mg}$ & $250 \mathrm{mg}$ & $25 \mathrm{mg}$ & $7.5 \mathrm{mg}$ \\
\hline
\end{tabular}

A

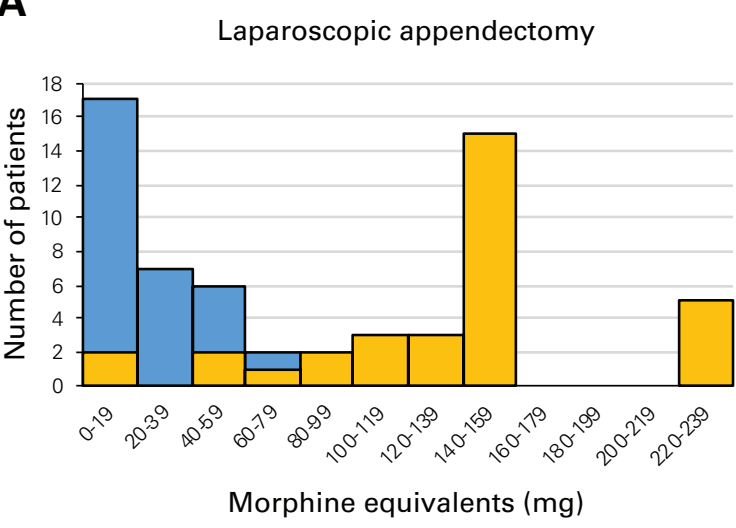

Laparoscopic cholecystectomy

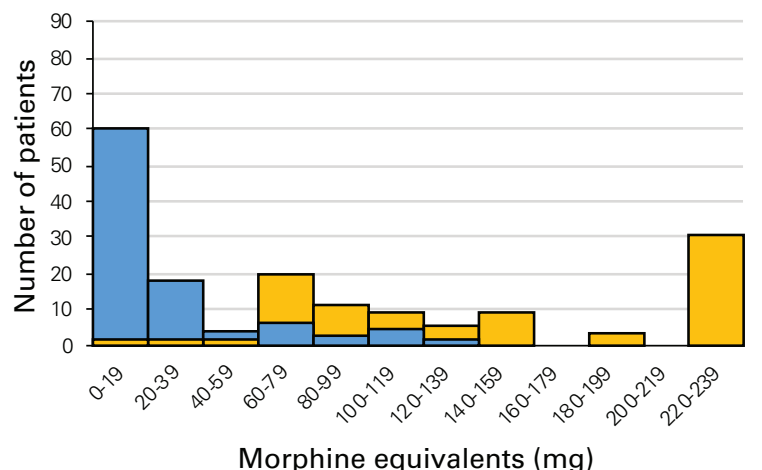

B

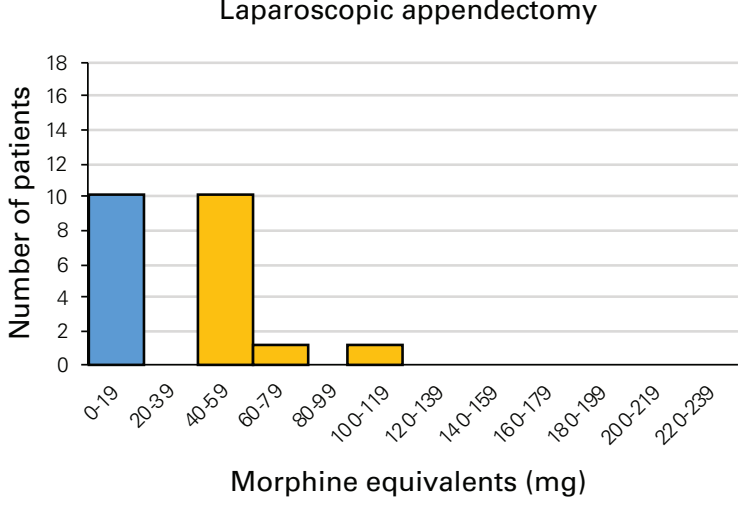

Laparoscopic cholecystectomy

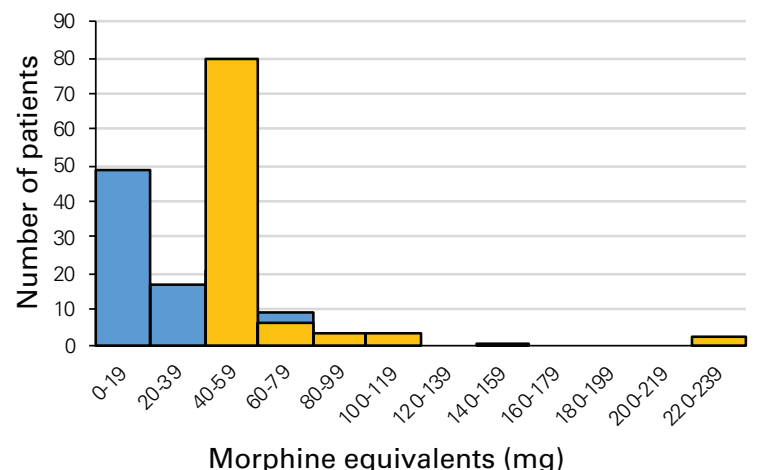

Fig. 1. Histogram of opioid prescription (yellow) and use (blue)by surgical procedure during the first $(A)$ and second $(B)$ phases of the study. 
prescription included the option for the patients to return 3 days later for another 10 pills to be dispensed, for a total of 20 pills. An optional 3-day supply of acetaminophen and/or ibuprofen was also included in the standardized electronic prescription order set. The entire prescription was written to expire after 1 month. Once consensus was reached, this standardized prescription was created in the electronic health record to facilitate compliance and standardization of discharge postoperative pain medications for both LA and LC patients.

\section{Second phase}

From November 2017 to January 2018, there were 95 LAs and 217 LCs performed at our hospital. Of these, 139 patients were successfully recruited using the same criteria as the first phase, with 30 lost to follow-up, resulting in a total of 109 patients (including 11 patients undergoing LA patients and 98 patients undergoing LC). The baseline characteristics of the second phase participants are displayed in Table 1. Similar to the first phase, there were a higher proportion of LA (91\%) than LC patients $(15 \%)$ who required emergency operations. Again, most patients were discharged on postoperative day zero or one. There was a higher proportion of female patients in the LC group (78\% v. 64\%).

Eighty-nine patients (82\%) received the new standardized prescription. A total of 1192 pills were prescribed and 238 (20\%) were consumed. The median number of pills prescribed was 10 (IQR 10-10), accounting for a median of 0 MME (IQR 0-20) consumed. Three patients returned to the pharmacy to fill the optional additional 10 pills available in their prescription. No patients required additional opioid prescriptions after discharge from hospital.

Compared with the first phase, the standardized prescription led to significantly fewer opioid pills filled (phase 1 median 20, phase 2 median $10, p<0.001$ ). Interestingly, this also led to significantly fewer opioid pills consumed (phase 1 median 2, phase 2 median 0 , $p=0.006$ ), although in both phases, this number was well below the 10 pills allowed for by our standardized prescription. There was a significantly higher percentage of patients who received education on opioid use and disposal $(8 \%$ in phase $1,44 \%$ in phase $2, p<0.001)$. However, this did not translate to increased proper disposal practices at the time of interview (4\% in phase $1 \mathrm{v} .3 \%$ in phase $2, p=0.88$ ). Despite decreased opioid prescription and use, there was no difference in pain scores or patient satisfaction with pain control (Table 4).

Using data from both phases, it was evident that the number of pills prescribed was positively associated with the number of pills consumed, $(r=0.2, p=0.007)$ and thus the number of MME consumed $(r=0.29, p<0.001)$. The standardized prescription was associated with a decrease in the number of pills prescribed $(p<0.001)$ and

\begin{tabular}{|c|c|c|c|}
\hline Outcome & $\begin{array}{c}\text { Before } \\
\text { intervention } \\
(n=127)\end{array}$ & $\begin{array}{c}\text { After } \\
\text { intervention } \\
(n=109)\end{array}$ & $p$ value \\
\hline $\begin{array}{l}\text { Number of pills filled, } \\
\text { median (IQR) }\end{array}$ & $20(15-30)$ & $10(10-10)$ & $<0.001$ \\
\hline $\begin{array}{l}\text { Number of pills consumed, } \\
\text { median (IQR) }\end{array}$ & $2(0-5)$ & $0(0-4)$ & 0.006 \\
\hline $\begin{array}{l}\text { Number of morphine milligram } \\
\text { equivalents consumed, } \\
\text { median (IQR) }\end{array}$ & $15(0-36)$ & $0(0-20)$ & 0.001 \\
\hline $\begin{array}{l}\text { Received education on opioids, } \\
\text { no. (\%) }\end{array}$ & $10(7.8)$ & 48 (43.6) & $<0.001$ \\
\hline $\begin{array}{l}\text { Pain score (out of } 10 \text { ) at } \\
\text { postoperative day } 7 \text {, median (IQR) }\end{array}$ & $4(2-5)$ & $4(3-5)$ & 0.97 \\
\hline $\begin{array}{l}\text { Satisfaction score; somewhat } \\
\text { satisfied or better, no. (\%) }\end{array}$ & $\begin{array}{c}122 \\
(96.1 \%)\end{array}$ & $\begin{array}{c}105 \\
(96.3 \%)\end{array}$ & 0.61 \\
\hline
\end{tabular}

MME consumed $(p=0.027)$. The number of MME prescribed was not correlated with the pain score $(r=0.09$, $p=0.16)$ but the number of MME consumed was correlated with the pain score $(r=0.29, p<0.01)$.

\section{Factors associated with opioid consumption}

A generalized linear model was used to determine factors associated with the number of MME consumed. Number of prescribed pills, age, sex, and history of addiction, psychiatric illness or chronic pain were not independently associated with consumed MME. LA was independently associated with more consumed MME compared with LC $(p=0.03)$, as did patients who underwent elective surgery $(p=0.03)$.

\section{Discussion}

This study indicates that at a Canadian, universityaffiliated community teaching hospital, patients are using substantially fewer opioids than prescribed after LA or LC. Over a 3-month period, a total of 2672 pills were prescribed for all patients undergoing either LA or LC, and only 458 (17\%) were consumed. At least onethird of patients did not use any opioid pills, stating that their pain was well-managed with non-opioid analgesics such as acetaminophen or ibuprofen. These findings are important because providers overestimate the number of opioid pills required. In a survey of surgical residents, the average prescription for LC was $166 \mathrm{MME}$, while the residents believed that their patients required only 114 MME. ${ }^{22}$ In the first phase of our study, patients used a median of $10 \mathrm{MME}$, much less than both what the residents prescribed and what the residents perceived was needed. These results are also considerably lower than those of a recent American study that reported that $80 \%$ of LC patients used 15 or fewer 
pills. ${ }^{17}$ The results of this study were used to develop a standardized opioid prescription after LA and LC that also included non-opioid analgesics (ibuprofen and/or acetaminophen). During the second phase of the study, the median number of opioid-containing pills prescribed decreased from 20 to 10 . Consumption remained at $20 \%$ of pills prescribed, but the average number of unused pills decreased from 17 to 9 per patient compared to the first phase. A greater proportion of patients received education regarding opioid use and disposal. Pain scores and patient satisfaction with pain control were unchanged between the 2 phases.

Perceived resistance to the development or use of a standardized prescription may stem from providers' perception that pain management must be individualized to a particular patient. This study included patients with pre-existing conditions that may have complicated their analgesia. However, on multivariate analysis, psychiatric conditions such as anxiety or depression, or history of chronic pain were not associated with increased opioid use, suggesting that these patients likely do not need to be prescribed increased quantities of opioids at the outset. A further barrier to limiting the amount of prescribed opioids is the belief that patients and providers will be inconvenienced by the need to organize refills. In this study, no patients required a refill for their prescription on or before postoperative day 7, and there was greater than $95 \%$ satisfaction with pain control. Furthermore, after implementation of the standardized and limited opioid prescription, patients took significantly fewer opioid pills without any change in their pain scores or satisfaction.

It has previously been shown that opioid prescription size is the strongest predictor of consumption..$^{23}$ Our results are very similar to those of the STOP Narcotics intervention. ${ }^{24}$ In this study, an educational intervention, combined with a standardized multimodal prescription, resulted in a median prescription of $50 \mathrm{MME}$ with no increase in the need for refills. In another large series of postoperative patients, the probability of requiring a refill of their opioid prescription was $9 \%$, but this was not correlated with the amount initially prescribed. ${ }^{25}$ Given the current opioid epidemic, it is not ethical to overprescribe in an attempt to obviate the need for refills.

In the first phase of this study, we identified that fewer than $10 \%$ of patients received information regarding proper disposal and storage of unused opioids, and an even smaller number had disposed of such appropriately. Using standardized patient education material, the frequency of educated patients increased to $44 \%$ but this did not translate into increased use of proper opioid storage or disposal practices. There is a lack of awareness regarding what constitutes appropriate disposal. The United States Food and Drug Administration endorses returning unused medications to authorized collection facilities such as pharmacies; where collection facilities are not available, medication can be mixed with dirt or kitty litter, sealed in a plastic bag and disposed with the trash. ${ }^{26}$ Opioids are considered to be particularly harmful if accidentally ingested, so flushing them down the toilet is recommended if proper disposal methods are not readily available. ${ }^{26}$ National prescription drug take-back days are held periodically in both Canada and the United States to help raise awareness and increase compliance. ${ }^{27,28}$ Providing patients with information should be an essential part of safe discharge from hospital, but is not enough to effect change. Future work should consider ways to incentivize opioid returns or make it more convenient by facilitating the return of unused medication at the postoperative visit.

\section{Limitations}

This study has several limitations. We surveyed patients to obtain data regarding the number of pills taken. This is subject to both recall bias and reporting bias, given the negative associations with opioid use. We also do not have detailed information regarding the quantity of adjuncts used, such as acetaminophen and nonsteroidal anti-inflammatory drugs, or the intraoperative use of local anesthetic. Furthermore, we did not collect individual prescriber information, including whether prescriptions were made by resident or staff physicians, and we are therefore unable to account for clustering. This would have been relevant when analyzing the amount of opioid prescribed, but is unlikely to impact the amount of opioid taken. Reported common practice is to provide patients with 30 opioid-containing pills after most surgical procedures, which is similar to our findings. ${ }^{17,29-31}$ Therefore, we feel that the opioid prescribing observed in our study is representative of general practices. Finally, the number of patients with either a history of long-term opioid use or addiction history included in our study was small, compromising our ability to generalize our conclusions to this population.

\section{Conclusion}

Opioids are prescribed in excessive quantities after laparoscopic appendectomy and laparoscopic cholecystectomy compared with what is clinically necessary to achieve adequate analgesia and patient satisfaction. In this single centre, more than 2000 excess opioid tablets were prescribed over the first study period that were not used by the patient. Introduction of a standardized prescription was effective in decreasing the number of opioid pills prescribed without any decrease in patient analgesia satisfaction or increased need for refills. There are still barriers to implementing safe storage and disposal of unused opioid medication, that may result in excess opioid being 
diverted and contributing to the opioid crisis. Future work will be focused on the development of a clinical practice guideline for opioid prescription that encompasses a broad variety of surgical procedures, as well as working on more effective interventions to ensure proper disposal for unused opioids.

Affiliations: From the Department of Colorectal Surgery, Cleveland Clinic Foundation, Cleveland, Ohio, USA (Feinberg); the Department of Surgery, University of Toronto, Toronto, Ont. (Acuna); the Department of Surgery, North York General Hospital, Toronto, Ont. (Smith); the Department of Anesthesia, North York General Hospital, Toronto, Ont. (Kashin, Mocon, Yau, Srikandarajah) and the Department of Pharmacy, North York General Hospital, Toronto, Ont. (Chiu).

\section{Competing interests: None declared.}

Contributors: A. Feinberg, A. Mocon, B. Yau, J. Chiu, S. Srikandarajah contributed to the conception and design of the study. D. Smith, B. Kashin, A. Mocon, B. Yau, J. Chiu, S. Srikandarajah acquired data. A. Feinberg, A. Mocon, S. Srikandarajah contributed to analysis and interpretation. A. Feinberg, A. Mocon, S. Srikandarajah wrote the article. All authors provided a critical review of the article and gave final approval for publication.

Content licence: This is an Open Access article distributed in accordance with the terms of the Creative Commons Attribution (CC BY-NC-ND 4.0) licence, which permits use, distribution and reproduction in any medium, provided that the original publication is properly cited, the use is noncommercial (i.e., research or educational use), and no modifications or adaptations are made. See: https://creativecommons.org/licenses/by-nc-nd/4.0/

\section{References}

1. McLellan AT, Turner B. Prescription opioids, overdose deaths, and physician responsibility. 7AMA 2008;300:2672-3.

2. Lucas CE, Vlahos AL, Ledgerwood AM. Kindness kills: the negative impact of pain as the fifth vital sign. 7 Am Coll Surg 2007;205:101-7.

3. Vital signs: overdoses of prescription opioid pain relievers - United States, 1999-2008. MMWR Morb Mortal Wkly Rep 2011;60:1487-92.

4. Dhalla IA, Mamdani MM, Sivilotti ML, et al. Prescribing of opioid analgesics and related mortality before and after the introduction of long-acting oxycodone. CMA7 2009;181:891-6.

5. Gomes T, Mamdani MM, Paterson JM, et al. Trends in high-dose opioid prescribing in Canada. Can Fam Physician 2014;60:826-32.

6. Wunsch H, Wijeysundera DN, Passarella MA, et al. Opioids prescribed after low-risk surgical procedures in the United States, 20042012. FAMA 2016;315:1654-7.

7. Alam A, Gomes T, Zheng H, et al. Long-term analgesic use after low-risk surgery: a retrospective cohort study. Arch Intern Med 2012;172:425-30.

8. Clarke H, Soneji N, Ko DT, et al. Rates and risk factors for prolonged opioid use after major surgery: population based cohort study. BMf 2014;348:g1251.

9. Soneji N, Clarke HA, Ko DT, et al. Risks of developing persistent opioid use after major surgery. FAMA Surg 2016;151:1083-4.

10. Manchikanti L, Singh A. Therapeutic opioids: a ten-year perspective on the complexities and complications of the escalating use, abuse, and nonmedical use of opioids. Pain Physician 2008;11:S63-88.

11. Finkelstein Y, Macdonald EM, Gonzalez A, et al. Overdose risk in young children of women prescribed opioids. Pediatrics 2017;139: e20162887.
12. Boak A, Hamilton HA, Adlaf EM, et al. Drug use among Ontario students 1977-2017: detailed findings from the Ontario Student Drug Use and Healthy Survey (OSDUHS) 2017. CAMH research document series no. 46, Toronto: Centre for Addiction and Mental Health. 2017.

13. Gomes T, Mamdani MM, Dhalla IA, et al. The burden of premature opioid-related mortality. Addiction 2014;109:1482-8.

14. Busse JW, Craigie S, Juurlink DN, et al. Guideline for opioid therapy and chronic noncancer pain. CMAJ 2017;189:E659-66.

15. OPEN. Opioid prescribing recommendations for surgery. Available: www.opioidprescribing.info (accessed 2019 Jun. 13).

16. Surgery BPi. Prescription and Management of Opioids after Surgery. Available: www.bestpracticeinsurgery.ca/guidelines/ prescription-and-management-of-opioids-after-surgery (accessed 2019 Jun. 13).

17. Hill MV, McMahon ML, Stucke RS, et al. Wide variation and excessive dosage of opioid prescriptions for common general surgical procedures. Ann Surg 2017;265:709-14.

18. Thiels CA, Anderson SS, Ubl DS, et al. Wide variation and overprescription of opioids after elective surgery. Ann Surg 2017; 266:564-73.

19. Feinberg AE, Chesney TR, Srikandarajah S, et al. Opioid use after discharge in postoperative patients: a systematic review. Ann Surg 2018;267:1056-62.

20. Bartels K, Mayes LM, Dingmann C, et al. Opioid use and storage patterns by patients after hospital discharge following surgery. PLoS One 2016;11:e0147972.

21. Horton JN. Nominal group technique: a method of decision-making by committee. Anaesthesia 1980;35:811-4.

22. Chiu AS, Healy JM, DeWane MP, et al. Trainees as agents of change in the opioid epidemic: optimizing the opioid prescription practices of surgical residents. F Surg Educ 2018;75:65-71.

23. Howard R, Fry B, Gunaseelan V, et al. Association of opioid prescribing with opioid consumption after surgery in Michigan. $7 A M A$ Surg 2019;154:e184234.

24. Hartford LB, Van Koughnett JAM, Murphy PB, et al. Standardization of outpatient procedure (STOP) narcotics: a prospective noninferiority study to reduce opioid use in outpatient general surgical procedures. 7 Am Coll Surg 2019;228:81-88e1.

25. Sekhri S, Arora NS, Cottrell H, et al. Probability of opioid prescription refilling after surgery: does initial prescription dose matter? Ann Surg 2018;268:271-6.

26. US Food \& Drug Administration. Disposal of unused medicines: what you should know. Available: www.fda.gov/Drugs/Resources ForYou/Consumers/BuyingUsingMedicineSafely/Ensuring SafeUseofMedicine/SafeDisposalofMedicines/ucm 186187.htm (accessed 2017 Jan. 22).

27. Canadian Association of Chiefs of Police. CACP national prescription drug drop-off day 2016. Available: www.cacp.ca/ cacp-national-prescription-drug-drop-off-day-2015.html (accessed 2017 Jan. 22).

28. Drugs.com. How to safely dispose of your old medications: national prescription drug take back day. Available: www.drugs.com/article/ medication-disposal.html (accessed 2017 Jan. 22).

29. Rodgers J, Cunningham K, Fitzgerald K, et al. Opioid consumption following outpatient upper extremity surgery. 7 Hand Surg Am 2012;37:645-50.

30. Voepel-Lewis T, Wagner D, Tait AR. Leftover prescription opioids after minor procedures: an unwitting source for accidental overdose in children. FAMA Pediatr 2015;169:497-8.

31. Maughan BC, Hersh EV, Shofer FS, et al. Unused opioid analgesics and drug disposal following outpatient dental surgery: a randomized controlled trial. Drug Alcobol Depend 2016;168:328-34. 